\title{
Methodologies to attain Graduate Attributes at Class Level
}

\author{
Kilari Veera Swamy \\ Professor, ECE Department, Vasavi College of Engineering, Ibrahimbagh, Hyderabad, Telangana, India. \\ k.veeraswamy@vce.ac.in
}

\begin{abstract}
Traditional teaching methodologies cover only 4 Graduate Attributes (GAs). These are GA1, GA2, GA3 and GA4. Remaining 8 Graduate Attributes will be accomplished with the new methods. In this work, activities based on active, cooperative, inductive, project, and emotional based learning methodologies are proposed. Proposed activities are designed by considering cognitive, psychomotor and affective domains of the blooms taxonomy. These activities are implemented at class level. In detail procedure to implement these methodologies in each course is presented. Hence, each course is mapped with more number Graduate Attributes. These methodologies include activities like the interactive sessions, group based assignments, case based assignments, and mini project in every course. Graduate Attributes like modern tool usage, individual/team work, communication, ethics, project management, and lifelong learning are better mapped with these new methodologies. Further, evaluation methods also proposed in this work. Experiments are performed on two classes of 60 students each. One class is taught by traditional teaching methods. Second class is taught by the proposed methodologies at course level. Performance of students in higher order thinking and lower order thinking is also assessed. Experimental results indicate that higher order thinking among students is improved. Hence, critical thinking is improved. Further, each course is mapped to 12 Graduate Attributes. Hence, possibility of attaining more Graduate Attributes is improved. Practice of proposed methodologies at class level improves the student's attendance.
\end{abstract}

Keywords: Graduate Attributes, Course Outcomes, Critical thinking, Co-operative Learning, Inductive Learning

\section{Introduction}

Objective analysis of facts to form a judgment is the critical thinking [1]. Definition generally contains the rational,

\footnotetext{
Kilari Veera Swamy

ECE Department, Vasavi College of Engineering, Hyderabad.

k.veeraswamy@vce.ac.in

sceptical, unbiased analysis, or evaluation of factual evidence. Critical thinking is self-directed, selfdisciplined, self-monitored, and self-corrective thinking. It presupposed assent to rigorous standards of excellence and good command to their use. Critical thinking plays a vital role in achieving Graduate Attributes (GAs) [10].
}

Graduate Attributes considered in this work are Engineering Knowledge(GA1), Problem Analysis(GA2), Design/Development of solutions (GA3), Conduct Investigation of Complex Engineering Problems(GA4), Use of Modern Engineering Tools(GA5), Engineer and Society (GA6), Environment and Sustainability(GA7), Ethics(GA8), Individual/Team work (GA9), Communications Skills(GA10), Project management and Finance(GA11), and Life Long Learning(GA12).

Critical thinking and various learning mechanisms are important to inculcate Graduate Attributes among students. It entails effective communication and problem-solving abilities, as well as a commitment to overcome our native egocentrism [2]. The earliest documentation of critical thinking is the teachings of Socrates recorded by Plato. Dr Benjamin Bloom created the Bloom's Taxonomy to improve higher order thinking in the education [3]. It is the stepping stone to move education from rote learning to higher order thinking such as analysing, evaluating and creating. It is most often used when designing educational, training, and learning processes. The outcome based education motivated me to do research on critical thinking $[4,5]$. Blooms proposed three domains. First one is cognitive domain. It is on knowledge based level. Second one is affective domain. It is on emotion based level. Third one is the psychomotor domain. It is on action (skill) based level. In each category, six levels are well defined [8, 9]. Important components in critical thinking are logic, argumentation, rhetoric, background knowledge and attitude [6]. Critical thinking enables the students to do better capability in interpretation, analysis, self-regulation, evaluation, explanation, and inference [7]. As per the Washington Accord the important graduate attributes are academic education, knowledge of engineering sciences, design/development of solutions, investigation, modern tool usage, individual/team work, communication, engineer and society, ethics, environment and sustainability, project management and finance, and lifelong learning[10]. Traditional methods limit the attributes to first four only.

Problems addressed in this work is impact of critical thinking on student learning outcomes and attainment of more number of GAs. In this work active, inductive and group learning is implemented on the batch of 60 students on one subject. Their learning graphs are observed over a 
period of 6 months. These learning methodologies can be implemented in technical, professional and management institutions. Improvement in their learning at higher order levels is good. Most of the educational institutions are practicing lower order thinking. Further all are limiting to the cognitive domain only. Other 2 domains like psychomotor and affective domains are neglected. In this work emphasis is given for all the three domains. These methodologies improve to meet other graduate attributes like GA5,GA6, GA7, GA8, GA9, GA10, GA11, and GA12. If we see any typical program either engineering or management, majority of the subjects/courses are mapped to first four Graduate Attributes only. Proposed methodologies in every subject/course help to map to all the Graduate Attributes.

\section{Proposed Methodologies}

Graduate Programs are required to impart knowledge, skills, and attitudes among students. The characteristics of a good graduate are identified as Graduate Attributes. Writing good Course Outcomes (COs) is the first key element in designing and conducting a course. Graduate attributes are achieved with the COs. Writing COs is done better through collaboration, and should be done through multiple iterations. Attainment of $\mathrm{COs}$ is measured through assessment [11] that is mostly in complete alignment with COs. Alignment means the assessment items are at the same cognitive level as represented by the action verb of the Course Outcome ( $\mathrm{CO})$ statement. Features of Good courses should address the entire GAs. It should address all the relevant cognitive and affective levels of learning. Course is planned to address active engagement of students with the new knowledge. Faculty members should be trained to assess students, about teaching and learning. Faculty members should interact well with the students. Have a good system of feedback, assessment, and grading, preferably using ICT tools. Incorporate experiences that can lead to attaining some of the professional Outcomes (GA6-GA12).Course Outcomes represent what the students should be able to do at the end of the course. Course Outcome statements should have the elements including action verb , categories of knowledge, conditions (optional), and Criteria (optional).For each $\mathrm{CO}$, we must decide: Marks to be allocated to this $\mathrm{CO}$ out of the total marks for CIE. The distribution of these marks are based on the relevant assessment instruments and the cognitive levels of the assessment items related to this CO. Accordingly Continuous Internal Evaluation (CIE) marks are allotted to COs. Marks allocated to a specific CO out of total CIE marks is the choice of the instructor with the only constraint being that every $\mathrm{CO}$ must have non-zero marks allocated to it. However, the instructor may wish to consider the following two parameters in deciding on the marks to be allocated. Proportion of classroom hours devoted to the $\mathrm{CO}$ and relative importance of this $\mathrm{CO}$ in later courses. Five methodologies and respective assessment procedures are proposed to attain more Graduate Attributes among the students at class level instead of program level. The majority of the universities are giving more importance to the Continuous Internal Evaluation (CIE). Here, the author has considered 40 marks for CIE in each course. Remaining 60 marks are allotted for Semester End Examinations (SEE). Only 15 marks are assigned for two internal examinations in the semester. Remaining 25 marks are assigned for the five proposed methodologies.

\section{A. Methodology 1(Active Learning):}

Active learning is implemented in the regular class Every class of 1 hour duration is divided into two parts. First part i.e., 45 minutes is allotted for instruction by the faculty. Second part i.e., 15 minutes is allotted for active learning. In every class, faculty and students interaction take place in these 15 minutes. Faculty should pose questions on the delivered topics. Questions should be framed by considering higher order thinking of blooms taxonomy. Students have to answer for the same in this session. This will help the students to improve their skills in the areas of socio-cultural, psychological, thinking, content learning and communication. 5 Marks are assigned for this activity out of 40 internal marks. In every session 4 students are covered in the interaction. Throughout the semester one student is covered thrice in that subject. In a semester one student is assessed almost 90 minutes in all the subjects' together. Student answer has a logical and conveys a meaningful answer with conclusion is awarded with 3 marks. Student answer has an uneven logical pattern and conveys a meaningful answer with lack of conclusion is awarded with 2 marks. The response has little logical pattern with no focus is awarded 1 mark. The response has no meaning is awarded with 0 mark. Effective communication is judged for 2 marks. Average marks are considered to finalize the marks for every individual student for 5 Marks. Here GA10 will be improved a lot apart from GA1 and GA2.

\section{B. Methodology 2(Co-operative Learning):}

Group assignment is assessed for 5 marks. In the group assignment every student has to explain his role in front of the evaluation team with clear documentation. Based on individual presentation each individual is assessed for 5 marks. 10 marks will be given to quality of the literature survey and references quoted. Team Collaboration and Professionalism will be assessed for 10 marks. Success level of the team to make the participants understand will be evaluated for 10 marks. Creativity in the presentation will be judged for 10 marks. Effectiveness in the presentation by the team will be assessed for 10 marks. Response to queries and proper citations are assessed for 10 marks. All these marks are scaled down to 5 marks by taking average and multiplying with $1 / 2$. Here GA8, GA9 and GA10 will be improved a lot apart from GA1 and GA2.

\section{Methodology 3(Inductive Learning):}

Inductive learning is implemented with case based assignment. Group of students have to submit the case based report to the concern teacher. Case Based Learning 
(CBL) promotes higher level of blooms taxonomy. It promotes various learning skills like collaborative learning, self reflection, critical reflection, knowledge integration, ethics and extrinsic motivation. Case based assignment is assessed for 5 marks. In the case based assignment 3 marks for report with solution and 2 marks for presentation skills are allotted. Here GA3. GA4, GA5,GA8, GA9 and GA10 will be improved a lot apart from GA1 and GA2.

\section{Methodology 4(Project Based Learning):}

Mini project is given here on the particular course. A Group of students have to submit the mini project report to the concerned teacher. Project Based Learning (PBL) is the method where students as a group work on real-world problems. These problems are framed in such a way that it should cover environment and society. The Teacher has to prepare these projects in association with the industry partners to improve the quality of the project. Sufficient time should be allotted for students to complete the mini project. It develops critical thinking, creativity, technology implementation skill, leadership, communication, ethics and collaborative skills among students. Mini project is assessed for 5 marks. Assessment contains three components. Skill is assessed for 3 marks. The report is assessed for 1 mark. Presentation is assessed for 2 marks. Skill assessment is as follows. A student who exhibits only imitation and manipulation will be given 01 mark. A student who exhibits precision and articulation will be given 02 marks. Students who possess naturalization will be given 03 marks. Naturalization is the highest taxonomy in psychomotor domain. Here GA3. GA4, GA5, GA8, GA9, GA10, GA11 and GA12 will be improved a lot apart from GA1 and GA2.

\section{E. Methodology 5(Emotional Learning):}

Attitude of the student is very important. In all above 4 methodologies separate sheet is designed to record student's attitude. Attitude assessment is further categorized based on affective domain of blooms taxonomy. It is in the scale of five levels i.e., receiving, responding, valuing, responsible behavior, and characterization. Averages of five activities in three methodologies are considered to finalize for the 5 marks. Receiving capable students will be given 1 mark. Responding capable students will be given 2 marks. Students who can follow with commitment and give justification will be given 3 marks. Students who prioritize time efficiently to receive, respond, value for self and organization will be given 4 marks. A student who displays a professional commitment to ethical practice and adaptability on a daily basis will be given 5 marks. GA6, GA7, GA8, and GA12 are mapped to the affective domain. The performance of the students are mapped to these attributes.

Now we shift our focus towards Graduate Attributes. Strength of CO to particular GA Mapping is explained here. Attainment of a GA depends both on the attainment levels of associated COs of core courses and the strengths to which it is mapped. Each Course Outcome addresses a subset of GAs to varying levels (strengths) $(1,2$ or 3$)$. It is necessary to determine the level (mapping strength) at which a particular GA is addressed by the course. Strength of mapping is defined at three levels: Low (1), Medium (2) and Strong (3). Strength of CO-GAs mapping a simple method is to relate the level of GA with the number of hours devoted to the COs which address the given GA. It is considered that GA is addressed at Level 3, If greater than $35 \%$ of classroom sessions/tutorials/lab hours addressing a particular GA. It is considered that GA is addressed at Level 2, If 20 to $35 \%$ of classroom sessions addressing a particular GA. It is considered that GA is addressed at Level 1, If 2 to $20 \%$ of classroom sessions addressing a particular GA. It is considered that GA is not-addressed, If less than $2 \%$ of classroom sessions addressing a particular GA.

Now we shift our focus to map Graduate Attributes to Blooms three domains i.e., cognitive, skill and affective domains. GA1, GA2, GA3, and GA4 are related to cognitive domain. GA5, GA9, GA10, and GA11 are mapped to the skill domain. GA6, GA7, GA8, and GA12 are mapped to the affective domain. Three important techniques used by the institutions to inculcate these attributes are teaching, learning, and assessment. Methodology 1 covers teaching, learning, and assessment. Further, this methodology covers cognitive domain (GA1 and GA2) and skill domain (GA10). Methodology 2 covers learning and assessment. Further, this methodology covers cognitive domain (GA1 and GA2), skill domain (GA9 and GA10), and affective domain (GA8). Methodology 3 covers learning and assessment. Further, this methodology covers the cognitive domain (GA1, GA2, GA3 and GA4), the skill domain (GA9 and GA10), and the affective domain (GA8). Methodology4 covers learning and assessment. Further, this methodology covers the cognitive domain (GA1, GA2, GA3 and GA4), the skill domain (GA5, GA9, GA10 and GA11), and the affective domain (GA6, GA7, GA8, and GA12). Methodology 5 is designed to measure the professionalism. Further, this methodology covers the affective domain (GA8 and GA12).

\section{Experimental Results}

Experiments are performed on two batches to observe improvement in critical thinking levels and attaining more GAs. Each batch contains 60 students. Batch 1 is taught with traditional teaching techniques. Batch 2 is taught with the proposed methodologies. Under graduate Course considered here is Computer Networks (CN) for Electronics and Communication Engineering program. Batch 1 students are assessed using three assignments, three quizzes and two internal exams. Five marks are assigned for average of best two assignments. Five marks are assigned for average of best two quizzes. Thirty marks are assigned by taking average of two internal examinations. Batch 2 students are assessed using proposed five methodologies and two internal exams. Performance in two internal exams is considered to assess the critical thinking among students. Assessment is conducted at various levels of bloom's taxonomy. $20 \%$ questions are from level 
1(remember). $20 \%$ questions are from level 2(understand). $20 \%$ questions are from level 3(apply). 20\% questions are from level 4(analyze). $10 \%$ questions are from level 5(evaluate). $10 \%$ questions are from level 6(create). Batch 1 student's average performance for 30 marks is presented in Table 1. Batch 2 student's average performance for 15 marks with multiplication of 2 is presented in Table 1 . Faculty concern has to take care while setting the question paper for two internal examinations. BLT level should be marked across each question in the question paper. Internal assessment taken as a whole must address all COs adequately. Ensuring this requires planning upfront. Tags including, Course Outcome Code, Competency Code, Cognitive Level, Knowledge Category, Difficulty Level, etc. Marks scored by each student based on the BLT level are added and divided by 60 to get the average marks. Here, BLT level is related to the cognitive domain. BLT levels in skill and affective domains are not considered while preparing question paper to avoid complexity. Rubrics allow for standardized evaluation according to specified criteria, making grading simpler and more transparent.

On an average Batch 2 students scored 4 marks more than Batch 1 students. Creation of new things with the existing knowledge is enhanced to $100 \%$. Evaluation capacity is increased to $66.6 \%$. Analysis capability is increased to $13.1 \%$. Applying skills are improved to $14.5 \%$. Hence, higher order thinking levels are improved with these methodologies. Overall improvement of $19 \%$ is observed with the proposed methodologies. Implementation of proposed methodologies in all courses can further improve the performance of the students. If we practice throughout the graduation period may further enhance the attainment of all Graduate Attributes with equal priority. Cognitive, affective, and psychomotor activities are related. These are not independent of one another. Higher levels of affective and psychomotor activities involve more and more cognitive activities. Instructors have to pay attention on these dependencies. Integration of psychomotor and affective elements into cognitive activities in engineering courses is essential. It further improves the student's performance. Students performance in analyze, evaluate, and create are the parameters to judge their critical thinking.

Table 1. Average Performance of students in Internal exams at various levels of Bloom's taxonomy

\begin{tabular}{|l|c|c|}
\hline \multicolumn{1}{|c|}{ BLT level } & $\begin{array}{c}\text { Traditional } \\
\text { methodologies } \\
\text { (Batch 1 Students) }\end{array}$ & $\begin{array}{c}\text { Proposed } \\
\text { methodologies } \\
\text { (Batch 2 Students) }\end{array}$ \\
\hline Remember(6M) & 5.4 & 5.6 \\
\hline Understand(6M) & 5.3 & 5.4 \\
\hline Apply(6M) & 4.2 & 5.2 \\
\hline Analyze(6M) & 4.1 & 4.8 \\
\hline Evaluate(3M) & 1.2 & 2.2 \\
\hline Create(3M) & 1.1 & 2.2 \\
\hline Total(30M) & $21.3(\mathrm{M})$ & $25.4(\mathrm{M})$ \\
\hline
\end{tabular}

Improvement percentage at various levels of BLT is shown in Fig 1. Improvement in higher order thinking is observed with the proposed methodologies.

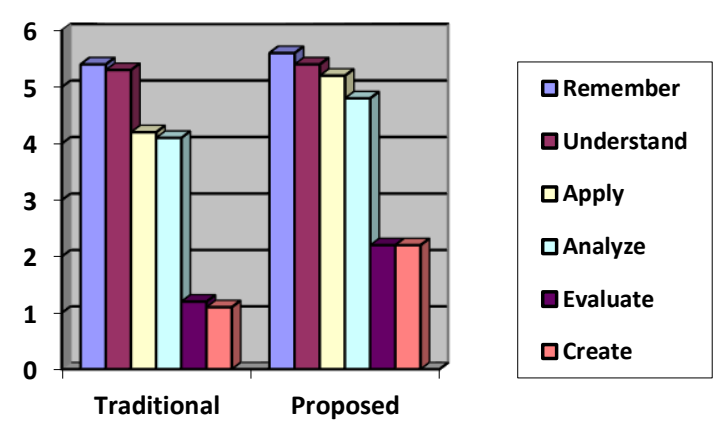

Fig. 1 Method wise distribution of average performance of students

Generally, we treat remembering, understanding, and applying are lower order thinking skills. Analyzing, evaluating, and creating are the higher order thinking skills. Batch 1 and Batch 2 student's average performance for lower order thinking and higher order thinking skills is presented in Table 2. Total marks considered for this are 40 marks. Higher order thinking skills are enhanced to $43.75 \%$. Lower order thinking skills are enhanced to $8.72 \%$. Hence, higher order thinking levels are improved with these methodologies. In turn critical thinking is enhanced with the proposed methodologies. Improvement in percentage at various thinking levels is shown in Fig 2.

Table 2. Average Performance of students in lower order thinking and higher order thinking

\begin{tabular}{|l|c|c|}
\hline \multicolumn{1}{|c|}{ BLT level } & $\begin{array}{c}\text { Traditional } \\
\text { methodologies } \\
\text { (Batch 1 Students) }\end{array}$ & $\begin{array}{c}\text { Proposed } \\
\text { methodologies } \\
\text { (Batch 2 Students) }\end{array}$ \\
\hline $\begin{array}{l}\text { Lower order } \\
\text { thinking (18M) }\end{array}$ & 14.9 & 16.2 \\
\hline $\begin{array}{l}\text { Higher order } \\
\text { thinking(12M) }\end{array}$ & 6.4 & 9.2 \\
\hline
\end{tabular}

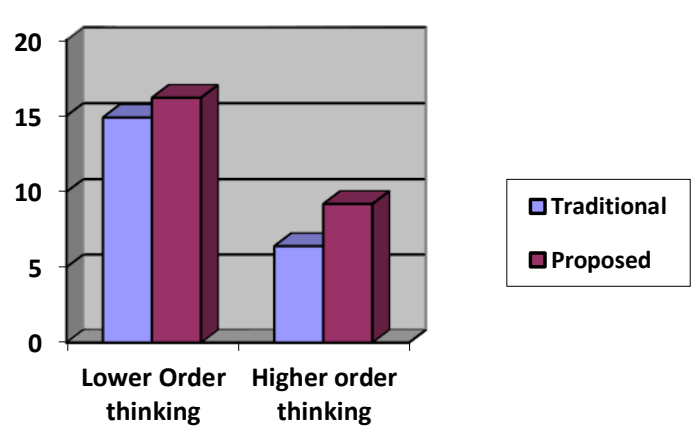

Fig. 2 Thinking performance of students

Now we shift our focus towards Graduate Attributes (GAs). Course outcomes for $\mathrm{CN}$ course are given below. Action, knowledge, condition, and criteria can be incorporated in 
CO statement. Action represents a cognitive/affective/ psychomotor activity the learner should perform. An action is indicated by an action verb, occasionally two, representing the concerned cognitive process(es). Knowledge represents the specific knowledge from any one or more of the four/eight knowledge categories. Condition represents the process the learner is expected to follow or the condition under which to perform the action (this is an optional element of $\mathrm{CO}$ ). The criterion represents the parameters that characterize the acceptability levels of performing the action (this is an optional element of $\mathrm{CO}$ ). At the end of the course, students are able to:

CO1: Understand the various network architectures.

CO2: Design and analyse the performance of LAN.

CO3: Judge the effectiveness of existing routing and congestion control algorithms.

$\mathrm{CO} 4$ : Create new and better protocols.

Course and GA mapping for Batch1 students is given below:

\begin{tabular}{|l|c|c|c|c|c|c|c|c|c|c|c|c|c|}
\hline Course & \multicolumn{10}{|c|}{ Mapping course with Graduate Attributes } \\
\hline & 1 & 2 & 3 & 4 & 5 & 6 & 7 & 8 & 9 & 10 & 11 & 12 \\
\hline CN & 3 & 3 & 1 & 1 & 0 & 0 & 0 & 0 & 0 & 0 & 0 & 0 \\
\hline
\end{tabular}

Course outcomes for $\mathrm{CN}$ course for Batch 2 students are given below. More graduate attributes can be attained by using the proposed methodologies. COs of the course are slightly modified based on the change in methodologies. At the end of the course, students are able to:

CO1: Understand the various network architectures.

CO2: Design and analyse the performance of LAN for software industries and educational institutes.

CO3: Judge the effectiveness of existing routing and congestion control algorithms.

$\mathrm{CO} 4$ : Create new and better protocols.

CO5: Write and present a substantial technical mini project reports to solve practical problems related to networks.

Course and GA mapping for Batch2 students is given below:

\begin{tabular}{|c|c|c|c|c|c|c|c|c|c|c|c|c|}
\hline Course & \multicolumn{10}{|c|}{ Mapping course with Graduate Attributes } \\
\hline & 1 & 2 & 3 & 4 & 5 & 6 & 7 & 8 & 9 & 10 & 11 & 12 \\
\hline $\mathrm{CN}$ & 3 & 3 & 2 & 2 & 1 & 1 & 1 & 1 & 2 & 2 & 1 & 1 \\
\hline
\end{tabular}

All the proposed methodologies involve the individual/team work with presentation opportunities. Hence, GA9 and GA10 are mapped with Level 2. Ethics are practiced by students during cooperative, inductive, and project based learning methodologies. Hence, GA8 is mapped with Level 1. While doing the mini project in the course student has to use modern tools. Hence, GA5 is mapped with Level 1. To complete the mini project, students should practice project management with lifelong learning skills. Hence, GA11 and GA12 are mapped with Level 1. Allocation of more number of hours in the respective activities can further improve the mapping levels.

Number of Graduate attributes can be attained using traditional method of teaching and proposed methodologies are presented in the Table 3 .

Table 3. Course mapping with number of Graduate Attributes

\begin{tabular}{|l|c|c|}
\hline & $\begin{array}{c}\text { Traditional } \\
\text { methodologies } \\
\text { (Batch1 Students) }\end{array}$ & $\begin{array}{c}\text { Proposed } \\
\text { methodologies } \\
\text { (Batch 2 Students) }\end{array}$ \\
\hline $\begin{array}{l}\text { Total Number } \\
\text { of Graduate } \\
\text { Attributes } \\
\text { mapped }\end{array}$ & 4 & 12 \\
\hline
\end{tabular}

Mapping levels of various Graduate Attributes are shown in Fig.3. Attainment is possible with mapping Course outcomes with more number of Graduate Attributes.

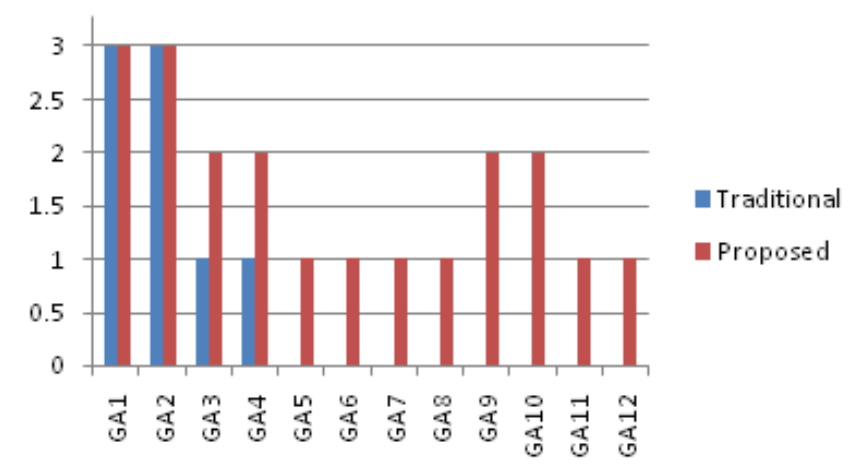

Fig. 3 Course mapping with Graduate Attributes

The characteristics (GA) of a good engineer are identified in India by National Board of Accreditation (NBA) as Program Outcomes. In this case GAs and POs are interchangeable headings.

\section{Conclusions}

Five methodologies are presented in this work to improve critical thinking and mapping the course with more Graduate Attributes. Integration of lower order thinking with higher order thinking is possible with the proposed methodologies. Overall higher order thinking is improved up to $43.75 \%$. Cognitive, skill and attitude domains are covered using these activities. Clear assessment procedures of the three domains are presented. Report submission and presentation is made mandatorily with the Methodology 2, Methodology 3, and Methodology 4 as a group. It enables the students to meet graduate attributes like individual/team work, communication, ethics, project management, and lifelong learning in every subject/course. Traditional method is mapped with only four Graduate Attributes. Proposed methodologies are able to map 12 Graduate Attributes. Mapping Levels of GA3 and GA4 are improved form Level 1 to Level 2. Hence, attainment of more 
Graduate Attributes is possible with the proposed methodologies. Regular practice of the suggested methods in all the subjects/courses will improve CO to GA mapping to level 3 over a period of time. Modification of assessment procedures in Semester End Examination system will further enhance the GA attainment.

\section{Acknowledgement}

The author would like to thank Management of Vasavi College Engineering for constant encouragement to implement new methodologies.

\section{References}

1. Edward M.Glaser (2017) defining critical thinking. The international center for the assessment of higher order thinking (icat,us)/critical thinking community. https://www.criticalthinking.org/pages/definingcritical-thinking/766

2. Jump up (2018) piagets stages of cognitive development.

http://www.telacommunications.com/nutshell/stages. htm

3. Bloom's taxonomy of learning domains: the cognitive domain.

http://www.nwlink.com/ donclark/hrd/bloom.html

4. Krain M. (2016) Putting the learning in case learning? The effects of case-based approaches on student knowledge, attitudes, and engagement. Journal on Excellence in College Teaching, 27(2), 131-153.

5. Bonney KM. (2015). Case Study Teaching Method Improves Student Performance and Perceptions of Learning Gains. Journal of Microbiology and Biology Education, 16(1): 21-28.

6. Kevin Delaplante (2018) Critical thinker academy: learn to think like a philosopher. https://www.udemy.com/course/critical-thinkeracademy/

7. Bloom's taxonomy of learning domains: the cognitive domain.

www. nwlink. com / donclark /hrd/bloom.html

8. Bloom B.S, Enelhart M.D, Furst E.J, Hill W.H, Krathwohl D.R(1956) taxonomy of educational objectives: the classification of educational goals. Handbook 1: Cognitive domain. New York.

9. Krathwohl David R(2002) A revision of bloom's taxonomy: an overview. Theory into practice. routledge.41(4):212-18. doi:10.1207/s15430421tip4104_2.ISSN 0040-5841.

10. International engineering alliance: rules \& procedures: international educational accords, Washington accord 1989, Sydney accord 2001, Dublin accord 2002.

http://www.ieagreements.org/rules-and-proceduresaug-2007.pdf

11. Kilari Veera Swamy and Ch Himabindu.(2018) Outcome Based Education for Effective Teaching and Assessment, International Conference on
Transformations in Engineering Education (ICTIEE AP' 18), SRM University, Amaravathi, July 15-17, 2018. 